\title{
Relato de observação de aluno com déficit intelectual em escola inclusiva
}

\author{
Zuleika Andradas Albuquerque \\ Universidade Federal de Santa Maria \\ (zukaalbuquerque@gmail.com)
}

\begin{abstract}
Resumo: Este relato de experiência apresenta o Relatório de Observação realizado junto a aluna com Déficit Intelectual que estuda em Escola Municipal de Ensino Fundamental de Porto Alegre. O Relatório de Observação faz parte da avaliação da Disciplina Alternativas Metodológicas para Aluno com Deficiência Mental, do Curso de Licenciatura da Educação Especial da Universidade Federal de Santa Maria. O objetivo foi observar como se dá a relação da aluna com a professora, os colegas e o ambiente escolar em uma visão teórica sociointeracionista de Vygotsky. Observou-se, também, se esses relacionamentos interpessoais favorecem o aprendizado da aluna, pois da mediação entre adulto-criança "teremos a formação das funções superiores, o que resultará na internalização de conhecimentos, ferramentas e signos por parte do aluno" (COSTAS, 2012). As observações realizaram-se em diferentes ambientes da escola: na sala de aula, com a professora titular ou referência; com a professora de Educação Física; com a professora de Arte Educação; com o Professor de Educação Especial, na Sala Integrada de Recursos; na aula de Dança; no pátio, durante o recreio; e no refeitório. Houve um acompanhamento do processo de ensino e aprendizagem da aluna e de como se dá a inclusão na escola.
\end{abstract}

Palavras-Chave: Déficit Intelectual; Teoria Sócio Interacionista; Inclusão.

\section{Report on the observation of an intellectually deficient student in an inclusive school}

Abstract: This report of experience presents the Report of Observation accomplished with an intellectually deficient student, from a primary municipal school of Porto Alegre. This report is an evaluation of the Methodological Alternatives for Students with Mental Disabilities discipline from the bacherlor's degree in special education of the Santa Maria University The aim is to see how the relation between the student and the t.eacher is, the colleagues and the school environment in a vision social interactionist theory of Vygotsky. Besides that to see if the interpersonal relationship indulges the student's learning, since "From adult-child mediation we will have the formation of the higher functions which will result in the student's internalization of knowledge, tools and signs". (COSTAS, 2012). The observations were made in different school environments: in the classroom with the physical education, art, special education and reference teachers, in the integrated resources and dance rooms, school's yard during break and in the canteen. There was a follow-up of the teaching process and the student's learning and how it is her inclusion in the school.

Keywords: Intellectual deficit; Interactionist social theory; Inclusion.

\section{INTRODUÇÃO}

Este artigo é um relato de experiência para mostrar o processo de construção do Relatório de Observação da Disciplina Alternativas Metodológicas para o Aluno com Deficiência Mental. Essa disciplina é obrigatória e consta na Grade Curricular da Licenciatura em Educação Especial do Centro de Educação - CE da Universidade Federal de Santa Maria - UFSM. Cabe aqui ressaltar que o termo 
Deficiência Mental ainda é utilizado, pois a disciplina não sofreu atualização. No decorrer do relatório, utiliza-se a nomenclatura Déficit Intelectual.

O Relatório de Observação compõe parte da avaliação da Disciplina Alternativas Metodológicas para o Aluno com Deficiência Mental e destina-se ao acompanhamento de aluna com Déficit Intelectual, em uma perspectiva teórica sociointeracionista Vygotskyana, que nos ajudará a compreender a sua constituição como sujeito a partir de suas relações e interações na escola. Para Vygotsky (apud COSTAS, 2012) o papel da coletividade é de suma importância como potencializador da evolução das funções superiores da criança em espaços educativos como a escola. Da mediação do adulto-criança teremos a formação das funções superiores, o que resultará na internalização de conhecimentos, ferramentas e signos por parte do aluno (COSTAS, 2012).

A aluna frequenta os anos iniciais do ensino fundamental, em escola regular da rede pública municipal de Porto Alegre. Tem Atendimento Educacional Especializado (AEE) na Sala de Integração e Recursos (SIR).

As observações basearam-se em roteiro disponibilizado pela professora orientadora, no qual foram priorizados alguns aspectos a observar, tais como: Qual o lugar da Educação Especial nesta escola? Como se dão as relações e interações entre os sujeitos envolvidos no processo de ensino e de aprendizagem? Em quais momentos e em que condições o aluno apresenta melhor desempenho? Quais metodologias os professores utilizam de maneira a proporcionar diferentes oportunidades de expressão do aluno? Também foram observadas as questões subjetivas do aluno, sua autonomia, suas preferências e seu autocuidado. Foram utilizados, também, para a observação, o Caderno Didático da disciplina e as leituras dos textos complementares.

A observação da aluna, com duração de quinze horas, realizou-se em diferentes ambientes da escola, possibilitando uma visão ampliada das suas interações e vivências, das mediações feitas através dos signos, da linguagem, dos professores com a aluna, dos colegas com a aluna, dos funcionários com a aluna e da aluna com o próprio ambiente escolar, a fim de compreender de que maneira essas mediações favorecem sua aprendizagem e seu desenvolvimento. Costas (2002) constata "como é importante para o desenvolvimento social de todo e qualquer indivíduo considerado com alguma necessidade especial o compartilhar de 
práticas educativas que valorizem os processos de inclusão. " (COSTAS, 2012, p. 190).

As atividades da aluna foram observadas na sala de aula com a professora referência, com a professora especializada de Arte e Educação, na oficina de Dança com a professora de Educação Física, na Sala de Integração e Recursos - SIR com o professor de Educação Especial, no pátio - durante o recreio - , e no refeitório, durante as refeições e o lanche.

\section{CONTEXTUALIZAÇÃO DO ESTÁGIO}

A aluna observada está no $3^{\circ}$ ano do primeiro Ciclo do Ensino Fundamental. Essa turma é integralizada e os alunos permanecem na escola em turno integral, das $8 \mathrm{~h}$ às 17h. Durante esse período, as aulas do currículo ocorrem com os professores referência e os especializados, além de haver diversas oficinas com os educadores sociais. Essas atividades abarcam Letramento, Horta, Recreação e até Dança.

Há um tempo expressivo em que as crianças podem interagir, o que proporciona o seu desenvolvimento em uma perspectiva sociointeracionista. Os alunos da turma A30 sentam-se em grupos heterogêneos, o que facilita a interação e a troca dos saberes.

Segundo Costas (2012, p. 134), a apropriação dos conceitos científicos pelos alunos se dá pela mediação através de signos e ferramentas presentes na cultura escolar, portanto, quanto maior o tempo em que a criança estiver na escola, maiores serão as mediações aluno-aluno, professor-aluno e aluno-adultos da comunidade escolar. Tais mediações irão proporcionar a aprendizagem e o acesso à zona de desenvolvimento proximal (ZDP), acarretando o desenvolvimento; ou seja, serão internalizados, pelas crianças, novos conceitos, novas aprendizagens.

\subsection{Revisitando O Histórico Da Educação Especial}

Para darmos continuidade a este relatório de observação de aluno com Déficit Intelectual, é importante que se faça um breve histórico de como tem sido tratada a 
pessoa com deficiência, ou os diferentes da normalidade, ao longo do tempo. Para isso, recorro às palavras de Menezes (2006).

Percorrendo diferentes períodos históricos decorrentes de lutas pelos direitos humanos, podemos afirmar, de forma sucinta, que as práticas educacionais desenvolvidas para as pessoas com NEEs, na maioria dos países, evoluíram da inexistência (período caracterizado pela segregação e exclusão), passando pela integração para chegar, nos dias atuais, à inclusão (MENEZES, 2006 p. 16).

As pessoas com deficiências eram excluídas ou abandonadas na Grécia Antiga, pois a sociedade necessitava de cidadãos fortes, sadios e com capacidade de raciocínio, prossegue a autora. Essa condição evoluiu para a segregação, após o advento do cristianismo, para quem o corpo do diferente era o resultado do pecado.

$\mathrm{Na}$ Idade Moderna, com o surgimento do Capitalismo, tem-se a premissa de que homens são máquinas e devem produzir, restando aos diferentes ou incapazes, ainda, a segregação. Quando da ascensão da burguesia, no séc. XVII, Menezes (2006, p.26) mostra que as diferenças começam a ser respeitadas, mas apenas nos grupos de poder, pois aos grupos sociais menos favorecidos só resta a legitimação da desigualdade.

No final dos anos 60, embora tenha início a institucionalização dos "deficientes", que passam a habitar instituições que visam à proteção, ao tratamento ou ao atendimento educacional, essas pessoas permaneceram segregadas e confinadas. A "normalização" das pessoas com deficiências ou diferenças ocorre com a Declaração Universal dos Direitos Humanos em 1948. Não era economicamente viável aos governos manter essas pessoas em instituições. Era melhor estarem livres e torná-las "normais", podendo ser aproveitadas como possível mão de obra. Tal modelo também não teve sucesso porque a sociedade não se preparou para receber essas pessoas diferentes.

A Integração proposta na sequência, causou, conforme Beyer (2015, p.75), "a criação de dois grupos de alunos: os que se encontravam acolhidos no sistema escolar, e... os outros que permaneciam fora do sistema e que constituem o alvo do movimento de integração". O foco estava centrado na Deficiência do aluno: ele que não aprendia, sendo agrupado entre "os que não aprendem". Somente a partir da Conferência Mundial de Jomtien, ocorrida na Tailândia entre 05 e 09 de março de 1990, em que foi assinada a Declaração Mundial sobre Educação para Todos, é que se passou a pensar na Educação Inclusiva - uma educação que dê conta de todas as pessoas. 


\subsubsection{Políticas De Educação Inclusiva Na Atualidade}

Percebe-se que a Educação Especial conseguiu firmar, através de muitas lutas e resistência, o seu espaço. Ela está contemplada, atualmente, nas políticas de inclusão escolar existentes. "No Brasil, as forças sociais se mobilizaram e convergiram para a Constituição Federal de 1988, que institui um Estado democrático e assegura, aos homens e mulheres, grandes conquistas sociais, " (ALBUQUERQUE, 2014, p.6). Nessa Constituição Cidadã de 1988, Menezes (2006, p.33) destaca o artigo 206, o qual prevê "a igualdade de condições de acesso e permanência na escola", bem como o atendimento educacional especializado aos portadores de deficiência, preferencialmente na rede regular de ensino.

A Declaração de Salamanca, fruto da conferência Mundial de Educação Especial ocorrida em 1994 na Espanha, reconhece a urgência do atendimento às pessoas com Necessidades Educacionais Especiais (NEEs) no sistema regular de ensino em classes heterogêneas, promovendo a interação entre as crianças. No Brasil, segundo Costas (2006, p. 37), em consonância com os preceitos da Declaração de Salamanca, elaborou-se, em 1996, a Lei de Diretrizes e Bases da Educação Nacional (LDBN 9394/96), a qual define e regulamenta o sistema de educação brasileiro. As atuais alterações da LDBN9394/96 se dão com base na constituição de 1988. No tocante à Educação Especial, a LDBN 9394/96 ainda era pautada pelo viés clínico terapêutico. Somente em 2013, com a Lei 12.796, em seu art.4ํㅡㄹ a Educação Básica passa a ser obrigatória dos quatro aos 17 anos para os alunos que conformam o público-alvo da Educação Especial.

Nos Governos dos Presidentes Lula (2003/2010) e Dilma Rousseff (2011/2016), ambos do Partido dos Trabalhadores (PT), temos mais publicações de leis relativas às políticas de inclusão escolar:

- Dec. № 5296/2004, que dá prioridade de atendimento para pessoas com Deficiência nos locais públicos.

- Decreto n. 5.626/05, publicado em 2005, que regulamenta a Língua Brasileira de Sinais - LIBRAS, e o art. 18 da Lei 10.098/2000, que trata da Acessibilidade das Pessoas com Deficiência.

- Política Nacional de Educação Especial na Perspectiva da Educação Inclusiva, em 2008. 
- Lei 12.796 de 2013, que altera LDBEN 9394/96, trazendo efetivos avanços para a Educação Especial e o Atendimento Educacional Especializado - AEE, obrigatório desde os quatro até os 17 anos.

- Lei 13146, de 06 julho 2015, que institui a Lei Brasileira de Inclusão da Pessoa com Deficiência, também conhecida como Estatuto da Pessoa com Deficiência.

"Entretanto, a publicação das leis por si só não garante o seu cumprimento, por isso se faz necessária a criação de políticas públicas que garantam a sua efetivação e o cumprimento de seus objetivos na busca por justiça social. " (ALBUQUERQUE, 2014, p.7). A publicação dessas leis visa garantir os direitos sociais desses grupos específicos e possibilita a implantação de políticas públicas para garantir-Ihes uma vida digna, em uma sociedade mais humana e mais justa preceitos da Declaração Mundial sobre Educação para Todos.

A superação das práticas segregacionistas só serão logradas quando a visão que se tem em relação às pessoas com deficiências mudar, quando o foco deslocarse de suas limitações - o que coloca barreiras em suas possibilidades de desenvolvimento colocando barreiras nas suas possibilidades de desenvolvimento, enquadrando-as e estigmatizando-as - para as suas potencialidades. Para que essa mudança de paradigma ocorra, é necessário que os professores busquem formação e disponham-se a conceber novos métodos e práticas para os alunos incluídos.

Fabris (2011) demonstra que nenhuma formação acadêmica irá ensinar tudo o que um professor precisa saber ao longo de sua carreira. É preciso que este esteja disposto a estudar sempre se quiser realmente incluir os alunos nos processos de ensino e aprendizagem.

A mera inclusão dos alunos com deficiência, sem preocupação com uma metodologia específica e alternativa que respeite as suas diferenças, não promoverá a sua aprendizagem, sendo benéfica apenas para a sua inserção social.

\subsubsection{A Escola Da Observação}

A observação realizou-se em Escola Municipal de Ensino Fundamental EMEF, considerada de pequeno porte, na Rede Municipal de Ensino (RME) de Porto Alegre. A escola conta com aproximadamente 500 alunos, tem seu funcionamento em dois turnos, pela manhã e à tarde, mantém sete turmas integralizadas ${ }^{1}$, de I e II

\footnotetext{
Turno integral: o aluno permanece na escola das $8 \mathrm{~h}$ às $17 \mathrm{~h}$.
} 
$\operatorname{ciclos}^{2}$ (JB, A10, duas de A20, duas de A30 e uma de B10), mais dez turmas de I, II e III ciclos atendidas em um turno único. Pela manhã, há duas turmas de C10, duas de C20 e uma de C30 (7응 $8^{\circ}$ e $9^{\circ}$ anos, respectivamente), e, à tarde, uma de B10, duas de B20 e duas de B30 (4ํㅜ $5^{\circ}$ e 6ํanos, respectivamente).

A EMEF está situada em um bairro de classe média baixa, na zona leste da periferia de Porto Alegre, em que a população da escola é constituída por filhos de trabalhadores e em grande parte em situação de vulnerabilidade social. (ALBUQUERQUE, 2015, p.74).

Mesmo em situações econômicas desfavoráveis, percebe-se, nas famílias, a valorização da educação escolar dos seus filhos, demonstrada por meio da participação das mesmas nas atividades voltadas à comunidade.

A escola conta com Biblioteca, Sala de Dança, Laboratório de Informática, Laboratório de Aprendizagem, Sala de Integração e Recursos - SIR, Refeitório, Sala de Professores, Secretaria, Sala da Direção, banheiros, horta, uma quadra aberta para esportes e pátio amplo.

\subsection{Contextualização Do Sujeito}

A aluna está com oito anos e é uma menina com desenvolvimento corporal dentro dos "padrões biológicos". É aluna em processo de inclusão escolar, através de protocolo da Sala de Integração e Recurso - SIR. Não possui laudo médico.

Quando da observação, demonstrou estar mais ativa e sorridente neste segundo semestre de 2016, aparentando estar mais confiante e participativa nas várias atividades observadas.

\subsubsection{Análise Do Parecer Pedagógico E História De Vida}

A aluna apresentou hidrocefalia quando pequena e foi necessária a introdução de uma válvula no cérebro, conforme relato da família. Apresenta um déficit cognitivo considerável em relação à alfabetização, não reconhece e não diferencia letras e números.

Sua aprendizagem se dá em ritmo lento na construção da lecto-escrita e numeralização. Não compreende as atividades e não estabelece relações com os conceitos estudados. As tarefas escolares não chamam a sua atenção.

\footnotetext{
2 As Escolas da RME de Porto Alegre têm seu Ensino Fundamental sob a forma de Ciclos de Formação, compreendidos de três ciclos de três anos cada, do1ํㅜ ao 9ํano.
} 
A partir das observações realizadas, percebe-se que o atraso na construção de suas aprendizagens está relacionado aos problemas de saúde, ao déficit intelectual, sendo necessário um movimento ainda maior da escola para que ocorra a sua interação com os colegas, além de mediações dos adultos com a aluna, pois, como nos ensina Vygotsky (1986 apud COSTAS, 2005, p. 28), a criança se constitui a partir do outro, "das relações que (...) estabelecem com o adulto, pois nessas relações interativas reside o seu caráter social".

Costas (2012) afirma que o desenvolvimento incompleto das funções superiores é uma superestrutura secundária à deficiência, corroborando a necessidade de mais atividades mediadas que promovam a interação da aluna na escola:

\begin{abstract}
O desenvolvimento incompleto provém do que se chama isolamento social da criança com necessidades especiais. A separação social ou a dificuldade de inserção social determina o desenvolvimento incompleto das funções superiores, as quais, quando acontecem seguindo a ordem das relações em sociedade, estruturam-se diretamente através do processo interativo da atividade coletiva da criança. (COSTAS, 2012, p. 57).
\end{abstract}

\title{
2.2.2 Análise De Estratégias Metodológicas Desenvolvidas Pelos Professores
}

Percebe-se que a preocupação com estratégias metodológicas para que a aluna e a turma atinjam seus objetivos ocorrem apenas nas aulas com a professora referência, com o professor de Educação Especial e com a professora de Educação Física que ministra a oficina de Dança.

$\mathrm{Na}$ aula de Arte e Educação, a professora não utilizou nenhuma estratégia alternativa ou específica. Observou-se que a aluna estava estática na sua classe, não compreendendo a proposta de pintar, recortar e montar um cenário típico das tradições gaúchas. Somente após algum tempo a professora incentivou a aluna a realizar o trabalho, elogiando-a depois. Observou-se, ainda, que a motivação ocorreu após a professora sinalizar em LIBRAS as figuras do gaúcho, da prenda, do chimarrão e do churrasco. Houve uma mudança, ainda que inesperada, na rotina da aula, o que lhe despertou a atenção.

$\mathrm{Na}$ oficina de Dança, com a professora de Educação Física, foi possível perceber que ela prepara estrategicamente as coreografias, de modo que a aluna esteja incluída, sem sentir-se sinta perdida e sozinha. Na coreografia, existem momentos em que as alunas se deslocam, colocando-se em círculos, para que a 
aluna realize perfeitamente os movimentos. A professora designa uma colega que interaja com ela, pegue-a pela mão e inicie o deslocamento, mas isso não é percebido pelo público, pois faz parte da coreografia.

O professor C., da SIR, utiliza-se de várias estratégias metodológicas: além de sugerir desenhos e escrita, ele propõe atividades corporais, plásticas e práticas para ocorra a aprendizagem por parte da aluna.

Como as observações deram-se próximas ao início da primavera, o professor C. estava trabalhando com o plantio de girassol, explorando o tema de várias formas. A aluna plantou as sementes em potes de iogurte, com terra preparada por ela, e colocou os vasinhos pendurados na cerca em frente à SIR. O professor solicitou que, em uma folha, ela colocasse seu nome e identificasse sua turma, de modo que na letra inicial do nome, desenhada por ele, fossem coladas sementes de girassóis. A aluna escreveu o nome e a turma, trocando e omitindo letras e números. No entanto, a colagem das sementes foi correta. Ele solicitou, ainda, que as palavras correspondentes aos materiais utilizados pelos alunos fossem escritas ou desenhadas na folha. A aluna teve dificuldade de lembrar da terra, da pá e do nome da flor, porém lembrava do potinho e da água que utilizaram no plantio. O nome correto só foi realizado após a intervenção do professor de Educação Especial.

A professora referência AC. mostra-se atenta às necessidades e dificuldades de seus alunos, utilizando várias estratégias metodológicas para que eles alcancem ou se aproximem dos objetivos propostos.

Ela trabalha com projetos pedagógicos, o que possibilita explorar diferentes maneiras de seus alunos se expressarem. No período das observações, eles estavam desenvolvendo a leitura e a produção de escrita utilizando pesquisas sobre os povos originários do Brasil.

O Projeto Curumim Contou, que consiste em trabalhar sobre a etnia Indígena Guarani, foi desenvolvido para conhecer e vivenciar a etnia Guarani ou o modo de ser Guarani "nhandereko". Através de músicas, danças, lendas, histórias dos sábios Guaranis, de visitação à aldeia, do contato com as crianças e com as professoras da Escola Indígena da aldeia Tehoa Pindó Mirim, em Viamão (RS), os alunos escreveram e ilustraram as histórias que compõem o livro.

A professora media as atividades de modo a potencializar a aprendizagem e 0 desenvolvimento da aluna com deficiência intelectual, possibilitando-Ihe construir conhecimentos por meio do exercício de sua atividade cognitiva, a qual é estimulada 
pela intervenção intencional da professora. Observa-se que ela partilha a ideia de que, no trabalho em grupo, os alunos ajudam-se mutuamente. Os que têm um pouco mais de conhecimentos auxiliam os outros, e todos constroem seus conhecimentos. Segundo Costas (2012, p.63), se "a escola se inclui na coletividade, todos os indivíduos constroem seus processos superiores em relações interativas".

\subsubsection{Análise Das Interações Estabelecidas No Contexto Escolar}

A aluna trabalha nos grupos da sala de aula interagindo de forma discreta com os colegas. Demonstra desinteresse pelas atividades relacionadas com a lectoescrita, certamente por não conseguir decifrá-las.

Mostrou habilidade e um certo interesse na ilustração da história para o Livro Curumim contou. Observou-se ela trabalhando em grupo, desenhando e pintando de forma lenta, de modo que os colegas precisavam estimulá-la e incentivá-la a realizar a tarefa. Isso evidencia que as mediações, mesmo sendo aluno-aluno, são propulsoras da aprendizagem ao serem alcançadas as zonas de desenvolvimento proximal, segundo Costas (2012). Ou seja, quando o aluno é afetado, motivado para a aprendizagem, atingirá a sua zona de desenvolvimento proximal e realizará a internalização dos conceitos.

Durante a aula de Arte Educação, a aluna coloriu o gaúcho e a prenda, realizando uma composição simples, mas com traçado visivelmente mais elaborado que o demonstrado no semestre anterior. Ainda dispersa-se brincando com outros materiais, como lápis, apontador e tesoura.

Não se percebeu, por parte da professora de Arte e Educação, no início da aula, uma mediação com a aluna. A turma tem muitos alunos, e há outros casos de alunos com Transtornos Globais do Desenvolvimento, o que dificulta a interação professora-aluna. A partir do momento em que a professora notou que a aluna não estava realizando a atividade, já na metade da aula, começou a incentivá-la, ao que a aluna respondeu de imediato, começando a colorir e compor o desenho. Percebese que a aluna precisa da intervenção do adulto, ou mesmo de um colega, para que, nesta mediação, atinja as funções psicológicas superiores, a zona de desenvolvimento proximal. Isso é corroborado por Costas (2012, p. 56), ao afirmar que "as funções psicológicas superiores têm procedência social", sendo assim fundamental que a aluna tenha sempre mediação de professores e colegas através 
de signos e de ferramentas adequadas, que podem ser a linguagem, o desenho ou a música.

Percebe-se também que, nas aulas com a professora referência AC., estabelecem-se diferentes situações mediadas pela linguagem (oral, visual e gestual), as quais irão promover a aprendizagem e o posterior desenvolvimento da aluna. Nesse sentido, Costas (2012, p.29) refere a importância da utilização dos conteúdos com significado para o aluno, pois "a acertada disposição do ensino dirigida à aprendizagem permite o desenvolvimento e a apropriação significativa dos conteúdos".

Constatou-se essa assertiva na realização do Projeto Curumin Contou, quando a aluna autora esteve empolgada na apresentação da dança e na sessão de autógrafos na $62^{\mathrm{a}}$ Feira do Livro de Porto Alegre. Via-se uma menina alegre e participativa, motivada para autografar, mesmo com as trocas de letras, nos livros dos leitores.

$\mathrm{Na}$ sala da SIR, a aluna desenvolve as atividades de escrita com a intervenção do professor, e, embora troque letras e números, esta dispõe-se a corrigi-los. Executou a atividade de plantio de girassóis com bastante habilidade e alegria, demonstrando que, para ela, as atividades motoras práticas são mais fáceis de realizar. Quando o professor C. solicitou-lhe que desenhasse o girassol a partir da imagem da tela do computador, foi necessário que ela levantasse e observasse várias vezes, sendo que seu desenho era instável. Em certo momento, pintou com o lápis de escrever e, quando o professor $\mathrm{C}$. Ihe indagou o motivo pelo qual utilizou tal lápis, respondeu que as folhas realmente estavam mortas, voltando a colorir com o lápis verde.

$\mathrm{Na}$ atividade em que deveria enumerar conceitos internalizados através de desenhos dos materiais utilizados para o plantio, não lembrava dos materiais, demonstrando não reter as informações, provavelmente em decorrência do Déficit Intelectual, o que dificulta a sua memorização. Conforme Costas, (2012, p. 26) "para interiorizarem-se, essas formas superiores estão sujeitas a transformações nas regras que regem sua atividade; elas interpenetram um novo sistema, que contém regras intrínsecas, interferindo diretamente no desenvolvimento do indivíduo." Percebe-se que não foi atingida a sua zona de desenvolvimento proximal. Faz-se necessária maior intervenção e mediação por parte dos professores da escola para 
que efetivamente os conceitos sejam internalizados pela aluna. Nesse sentido, Costas afirma que a

escolarização possui uma efetiva e imprescindível contribuição aos processos de desenvolvimento, posto que o sujeito que se encontra imerso em práticas escolares apresenta sensíveis diferenciações qualificativas em termos de progressos conceituais com relação àqueles que não participam dessas práticas específicas. (COSTAS, 2012, p. 132).

Em relação ao autocuidado, a aluna demonstra um avanço em relação ao semestre anterior, vestindo-se adequadamente, inclusive com as roupas da aula de balé, sendo que ainda conta com algum auxílio das colegas.

Foi possível observar maior responsabilidade com o horário da aula de balé e muita atenção durante as aulas de dança. Seus movimentos corporais são adequados. Os conceitos ligados à sua motricidade estão bem internalizados, pois são percebidos pelo seu desenvolvimento. Isso vai ao encontro do que afirma Costas quanto aos estudos e entendimentos de Vygotsky, apontando que " as funções superiores se desenvolvem em espaços interativos de aprendizagem, através de constante apropriação e internalização de ferramentas e signos culturais" (COSTAS, 2012, p. 21).

A aluna explora com autonomia os diversos espaços da escola: banheiros, refeitório, biblioteca. Principalmente no recreio, gosta de correr, pular, jogar bola e brincar na pracinha. Quando do ingresso de um novo colega na turma, ela o acolheu e são os melhores amigos no recreio, correndo o tempo todo. Foi difícil acompanhar as suas brincadeiras durante as observações. Vale ressaltar que o menino também apresenta dificuldades com a lecto-escrita.

\section{PROPOSTA DE ATUAÇÃO DO PROFESSOR DE EDUCAÇÃO ESPECIAL}

O professor de Educação Especial deve ser um elo entre o aluno e o processo de ensino e aprendizagem, os professores, os funcionários, a equipe diretiva e as famílias da comunidade.

Seu trabalho deve ir além da SIR, sendo necessário atuar junto ao professor referência, aos especializados, aos educadores sociais e aos estagiários de inclusão 
dos alunos da SIR, auxiliando na escolha das atividades, promovendo reuniões para que sejam elaborados, conjuntamente, os currículos adaptados, bem como os objetivos a serem desenvolvidos com a turma, possibilitando a aprendizagem e o desenvolvimento dos alunos. Deverá, também, participar do processo de avaliação.

O Professor de Educação Especial deverá marcar o espaço da SIR no contexto escolar, sistematizando reuniões com todo o grupo docente da escola, inclusive com os funcionários. Essas reuniões podem ser mensais, utilizando as Reuniões Pedagógicas semanais que são garantidas na Rede de Ensino Municipal.

É importante que também esteja presente nos Conselhos de Classe Participativos da turma que tiver alunos com Necessidades Educacionais Especiais NEEs.

Deve promover frequentemente o encontro das famílias de alunos de AEE, a fim de que elas possam se fortalecer com o convívio e com as trocas de suas expectativas, ansiedades, satisfações com os avanços, com as aprendizagens e com o desenvolvimentos dos seus filhos.

\section{CONSIDERAÇÕES E ENCAMINHAMENTOS FINAIS}

Não se poderia deixar de mencionar, neste relato, que, após o período das observações, ainda acompanhamos a turma, com o convite e o auxílio da professora referência. No encerramento da oficina de Dança, houve a apresentação artística dos alunos, e a aluna observada teve um bom desempenho. Contou com o auxílio de suas colegas, através das interações e estratégias alternativas propostas pela professora de Dança na coreografia inclusiva.

Outro fato positivo e significativo na vida dessa aluna foi a manhã de lançamento do Livro Bilíngue Curumin Contou = Kyringue omombe'u escrito pela sua turma e pelos alunos indígenas da Escola Estadual Nhamandu Nhemmop'Á, da Aldeia Indígena Guarani. A sessão de autógrafos ocorrida na 62a Feira do Livro de Porto Alegre iniciou-se com a apresentação de Dança e coreografia da resistência indígena. A aluna atuou com total autonomia e em perfeita sintonia com os seus colegas e com as canções.

Ela sentiu-se valorizada pelo lançamento do Livro que ajudou a construir. Isso teve um significado importante na sua vida, pois se vê como autora do projeto e, 
assim, tem a sua autoestima elevada. Junto com os colegas e os alunos indígenas Mby'a Guarani, pôde exercer a sua condição de autora, autografando na Feira do Livro os exemplares para quem os adquirisse.

Esses momentos de alegria compartilhada entre alunos e professores mostram que a escola pode e deve ser inclusiva, bastando que o professor encontre estratégias metodológicas capazes de desacomodar e motivar os alunos à aprendizagem, como nos mostrou Vygotsky em suas pesquisas (apud Costas, 2012), mediando o ensino e possibilitando que o aluno desenvolva as suas funções psicológicas superiores. Costas, referindo-se aos estudos de Vygotsky, lembra que "a aprendizagem é propulsora do desenvolvimento, concretizando-se no ser humano através de uma área de desenvolvimento proximal" (COSTAS, 2012, p.27).

Finalizamos este relato com as palavras de Costas (2012, p. 63): "Então todo o ser humano poderá, desde que sejam oferecidas estratégias de aprendizagem, apropriar-se de conceitos científicos". Nessa perspectiva de educação inclusiva, prosseguiremos nossos estudos da Licenciatura em Educação Especial com 0 objetivo de alcançarmos uma escola para todos.

\section{REFERÊNCIAS}

ALBUQUERQUE, Zuleika Andradas. Relações étnico-raciais negra: proposta de ação pedagógica em Escola Municipal de Porto Alegre. ScienciaTec:Revista de Educação, Ciência e Tecnologia, IFRS,Porto Alegre, v.2, n. 3, 2015. p. 71-92. Disponível em: $<$ https://periodicos.ifrs.edu.br/index.php/ScientiaTec/article/view/1451/1213> Acessado em 27 de mar. de 2017.

. As relações étnico-raciais negra e indígena na escola: Possibilidades de ações pedagógicas reduzindo o racismo. \# Tear: Revista de Educação, Ciência e Tecnologia, Canoas, v.3, n. 1, 2014. P. 1-13. Disponível em: <https://periodicos.ifrs.edu.br/index.php/tear/article/view/1856/1440>. Acessado em 27 de mar. de 2017.

BEYER, Hugo Otto. Da Integração Escolar à Educação Inclusiva: implicações pedagógicas. In: BAPTISTA, Cláudio Roberto (org.). Inclusão E Escolarização: múltiplas perspectivas. Porto Alegre: Mediação, 2015. p. 73 - 81.

BRASIL Lei 13146 de 06 julho de 2015, que institui a Lei Brasileira de Inclusão da Pessoa com Deficiência - Estatuto da Pessoa com Deficiência. Brasília. Disponível em: <http://www.planalto.gov.br/ccivil_03/_ato2015-2018/2015/Lei/L13146.htm>. Acessado em 01 de nov. de 2016.

COSTAS, Fabiane Adela Tonetto. A Escola Sócio-Histórica in MEURER, Ane Carine; [et al.] ; Psicologia da educação III : $3^{\circ}$ semestre.- 1. ed. - Santa Maria, Universidade Federal de Santa Maria, Pró-Reitoria de Graduação, Centro de Educação, Curso de Graduação a Distância de Educação Especial, 2005. 80 p. : il. ; 30 cm. 
Formação de conceitos em crianças com necessidades especiais: contribuições da teoria histórico-cultural. Santa Maria, RS: Editora UFSM, 2012.

FABRIS, Eli Terezinha Henn. Experiências De In/Exclusão No Currículo Escolar: desafios e complexidades. Disponível em: <http://www.anped.org.br/sites/default/files/gt13-479int.pdf $>$. Acessado em 01 de Nov. de 2016.

MENEZES, Eliana da Costa Pereira de. Informática e Educação Inclusiva: discutindo limites e possibilidades. Santa Maria: Ed. da UFSM, 2006.132p: $30 \mathrm{~cm}$.

SILVA, Ana Cristina Motta da; STEFANELLO, Patrícia Dias; SANTOS, Alessandra Teresinha Aguiar dos. Org. Curumin Contou = Kyringue omombe'u. Porto Alegre: Secco Editora, 2016. 72p.; il.; 28cm. 